\title{
The Effect of Benzotriazole and Phenyl-amino-triazine-dithiol on Corrosion Inhibition of Copper in Low-conductivity Water
}

\author{
Zhou Guo-ding*, Feng Yiqi* and Takenori Notoya** \\ * Electrochemical Research Group, Department of Thermal Power Engineering, \\ Shanghai Institute of Electric Power \\ ** Department of Metallurgical Engineering, Faculty of Engineering, \\ Hokkaido University
}

\begin{abstract}
Impedance measurements of copper electrodes in a low-conductivity water (less than $10 \mu \mathrm{S} /$ $\mathrm{cm}$ ) with the addition of either benzotriazole (BTA) or phenyl-amino-triazine-dithiol (PTD) were performed. BTA inhibits copper corrosion better than PTD. Corrosion inhibition with PTD occurs only at concentrations above $10 \mathrm{ppm}$. A combination of BTA and PTD proved more effective than either used alone. The optimum ratio is $3 \mathrm{ppm}$ BTA $+2 \mathrm{ppm}$ PTD with the total amount of inhibitor $5 \mathrm{ppm}$.
\end{abstract}

Key words: copper corrosion inhibition, low-conductivity water, mixed inhibitor, impedance measurement

\section{Introduction}

Water cooled generators are widely used in power plants. Low-conductivity water (less than $10 \mu \mathrm{S} / \mathrm{cm}$ ) flows through hollow copper conductors as the cooling medium and causes corrosion of the conductors. Therefore, corrosion inhibitors are important to protect copper conductors against corrosion and to operate generators safely and economically. Impedance measurements are effective approaches to the study of corrosion inhibition.

There are several papers on impedance measurements with benzotriazole (BTA) as a corrosion inhibitor for copper in sodium chloride solutions ${ }^{1) \sim 3)}$. However, there have no impedance studies on the inhibitive action on copper in low-conductivity solutions. This paper studies the inhibition of copper corrosion with BTA and $N$-phenyl-6-amino-1.3.5-triazine-2.4dithiol (PTD) in the low-conductivity solutions by impedence measurements.

\section{Experimental}

The chemical analysis of the low-conductivity solution is as follows; $\mathrm{O}_{2} 1.5 \sim 2 \mathrm{ppm}, \mathrm{NH}_{3}<1$

* Shanghai, Peoples Republic of China

** Kita 13 Jo Nishi 8 chome, Kita-ku, Sapporo, 060 Japan ppm, $\mathrm{SiO}_{2}<20 \mathrm{ppb}$, and $\mathrm{Na}^{+}<50$ ppb. Fig. 1 shows the chemical structure of BTA and PTD. A $99.9 \%$ pure copper electrode was with a sur-<smiles>Brc1cccc2[nH]nnc12</smiles>

Benzotriazole<smiles>O=P([O-])([O-])c1ccc(Nc2nc(S)nc(S(=O)(=O)c3ccccc3)n2)cc1</smiles>

N-Pheny 1-6-amino-1,3,5triazine-2, 4-dithiol mono sodium salt

Fig. 1 Chemical structure of the inhibitors 
face area of $1 \mathrm{~cm}^{2}$ and reagents were of analytical grade. The $\mathrm{pH}$ of the solutions were adjusted with ammonia water and kept at 7.4, and except the $40 \mathrm{ppm}$ PTD solution the conductivity of solutions was maintained at less than $10 \mu \mathrm{S} / \mathrm{cm}$. The use of ammonia water to adjust $\mathrm{pH}$ of solution is a common practice in most power plants in China. Since there was only a little amount of $\mathrm{NH}_{4}{ }^{+}$in the solution, it did not accelerate copper corrosion with forming ammonium-copper complex. Before every run the electrode surface was abraded with emery papers No. 2, 3, 4, and 5. The electrode was washed, degreased with acetone, rinsed with deionized water, and immersed in the solution in a cell.

Impedence measurements were performed at the corrosion potential in a three-electrode electrochemical cell at $30^{\circ} \mathrm{C}$ with at $\mathrm{Pt}$ electrode as a counter electrode and a saturated calomel electrode as a reference electrode with a PARC M 273 potentiostat, PARC 5208 EC lock-in amplifier, and PARC M 378 software system over a frequency range of $0.05 \mathrm{~Hz}$ to $100 \mathrm{kHz}$.

\section{Results and discussion}

The equivalent circuit for the electrode system with corrosion inhibitors is shown in Fig. 2, where $R_{1}$ is the solution resistance, $R$ the film resistance, $C$ the film capacitance, and $Z_{\mathrm{w}}$ the Warburg impedance ${ }^{2)}$. The $R$ and $C$ values can be determined from Bode plots, where the $R$ value can be calculated from the maximum phase angle, $\theta_{\max }$, and the corresponding value of the impedance modulus at $\theta_{\max }|Z|_{\theta, \max }$ according to

$$
R=2|Z|_{\theta, \max } \operatorname{tang} \theta_{\text {max }}^{4), 5)}
$$

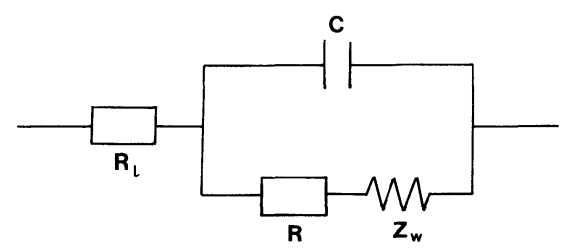

Fig. 2 Equivalent circuit for the copper electrode in low conductivity solutions containing corrosion inhibitors.

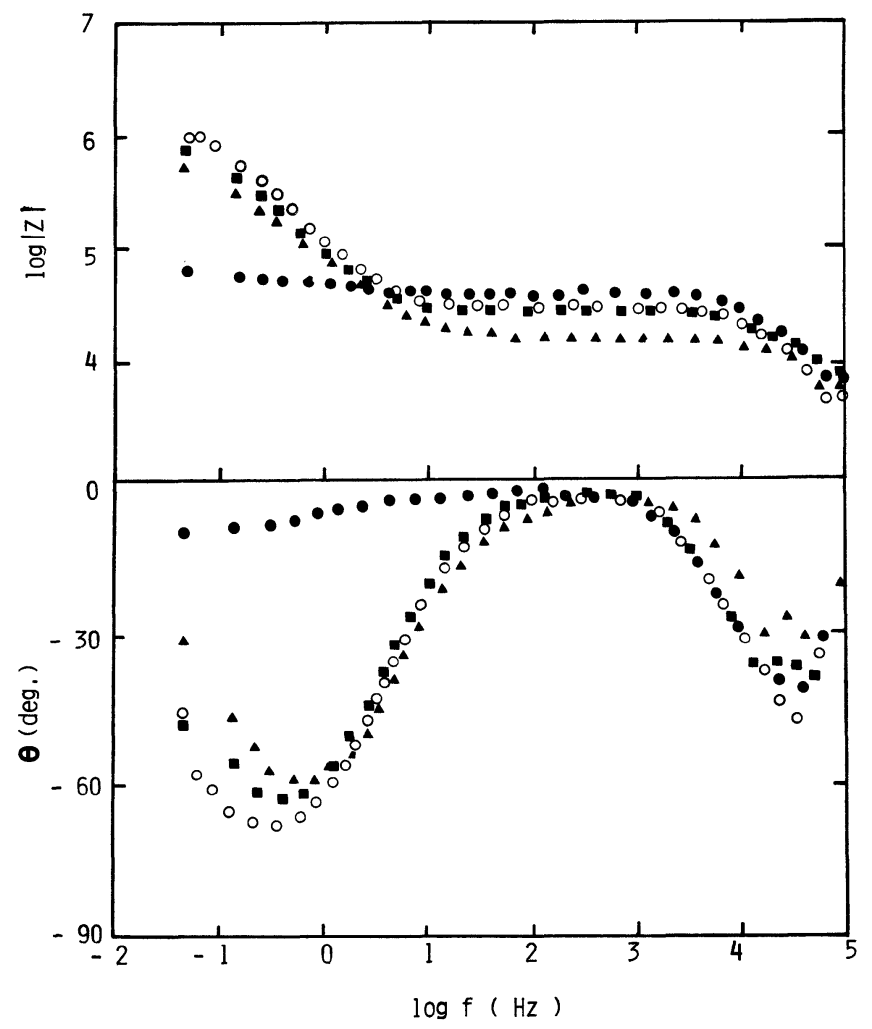

Fig. 3 Bode plots for copper electrodes $30 \mathrm{~min}$ after immersion in low conductivity solutions with the addition of BTA at $30^{\circ} \mathrm{C}$. BTA: $0 \mathrm{ppm} \bullet, 2 \mathrm{ppm} \wedge, 10 \mathrm{ppm} \mathbf{\square}, 40 \mathrm{ppm} \bigcirc$ 
and the $C$ values calculated from $|Z|_{\theta, \max }$ and the corresponding value of the frequency at $\theta_{\max }$, $f_{\theta, \max }$ according to the equation ${ }^{5)}$

$$
C=\frac{1}{2 \pi f_{\theta, \max }|Z|_{\theta, \max }}
$$

Fig. 3 shows Bode plots for copper electrodes after $30 \mathrm{~min}$ immersion in low-conductivity solutions with various BTA concentrations. Both the impedance modulus $|Z|$ and $\theta_{\max }$ increases with BTA concentration. With increased BTA concentration, $R$ increases and $C$ decreases as shown in Fig. 4. In addition, both $R$ and $C$ change markedly with the BTA concentrations below $5 \mathrm{ppm}$.

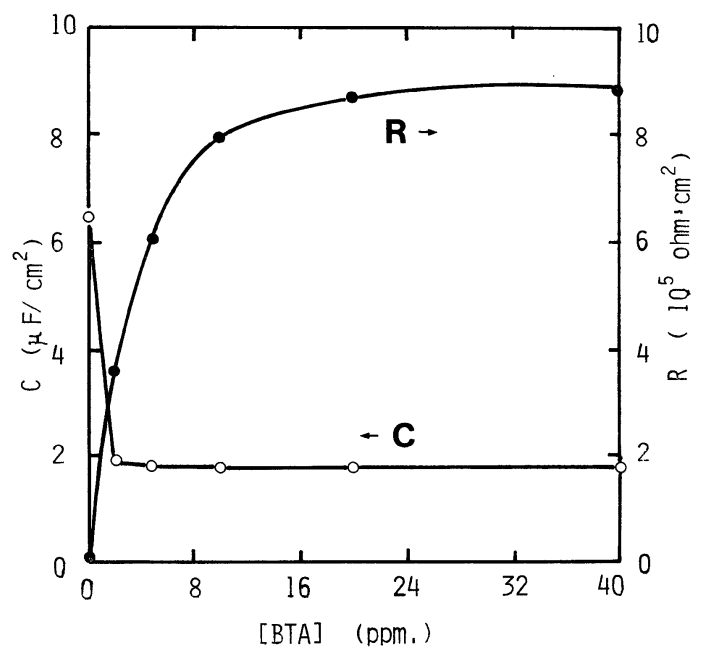

Fig. $4 R$ and $C$ vs. BTA concentration for copper electrodes after $30 \mathrm{~min}$ immersion in low conductivity solutions at $30^{\circ} \mathrm{C}$.
Fig. 5 shows $R$ and $C$ vs. immersion time with the addition of $5 \mathrm{ppm}$ BTA and that of $20 \mathrm{ppm}$ PTD. With increased immersion time $R$ increases and $C$ decreases. The changes in $R$ and $C$ due to the addition of BTA are attributed to the formation of a CuBTA protective film $\left.{ }^{2), 6}, 7\right)$. The film becomes thicker and more protective as BTA concentration and immersion time increase.

Mori et al. ${ }^{8)}$ reported that PTD reacted easily with copper oxides in water, and the chemical formula of the surface films formed on copper oxides would mainly be $\mathrm{C}_{6} \mathrm{H}_{5} \mathrm{NH}-\mathrm{C}_{3} \mathrm{~N}_{3} \mathrm{~S}_{2} \cdot 2 \mathrm{Cu}(\mathrm{I})$, as determined by infrared spectroscopy. For copper, and especially brass, PTD is an effective corrosion inhibitor ${ }^{9) \sim 11)}$, and inhibition appears at concentrations above $10 \mathrm{ppm}$.

Fig. 6-a, b, c, and d show Nyquist plots for copper electrodes $24 \mathrm{hr}$ after immersion in solutions containing $0,5,10$, and $20 \mathrm{ppm}$, respectively. In the absence of PTD (Fig. 6-a), a high frequency semicircle and a straight line are observed. The straight line with the slope of about 45 degrees appears at low frequencies, which represents Warburg impedance due to the diffusion of dissolved oxygen in the solution. It implies that the corrosion reaction of copper in the absence of PTD is dominated by the diffusion of dissolved oxygen. The high frequency semicircle can be mainly attributed to the reference electrode system in the cell ${ }^{122}$. (We are studying this phenomenon further and will publish results separately.) The impedance locus in Fig. 6-b is similar to that in Fig. 6-a. In Fig. 6-c, the second semicircle appears in

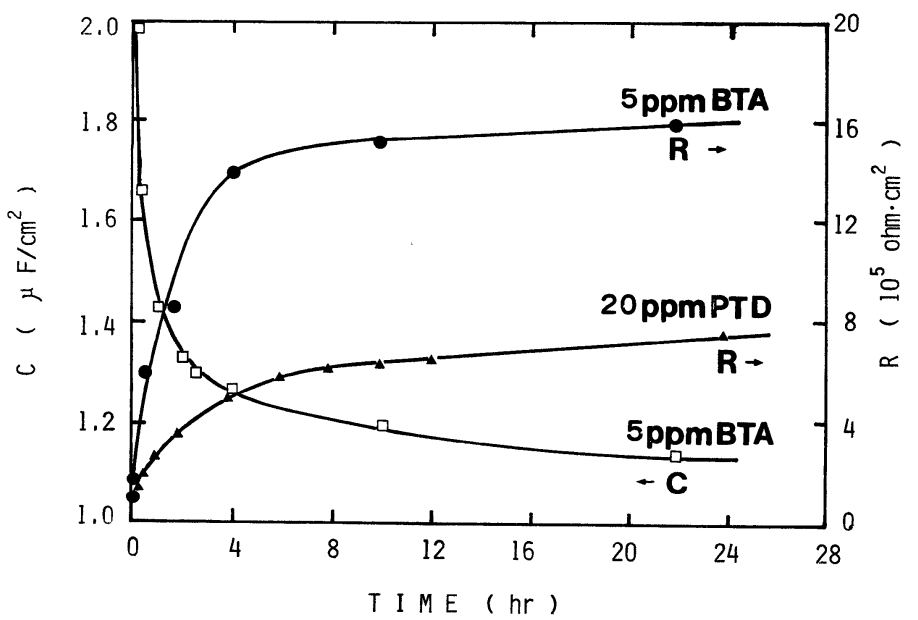

Fig. $5 R$ and $C$ vs. immersion time for copper electrodes in low conductivity solutions with $5 \mathrm{ppm}$ BTA and $20 \mathrm{ppm}$ PTD at $30^{\circ} \mathrm{C}$. 

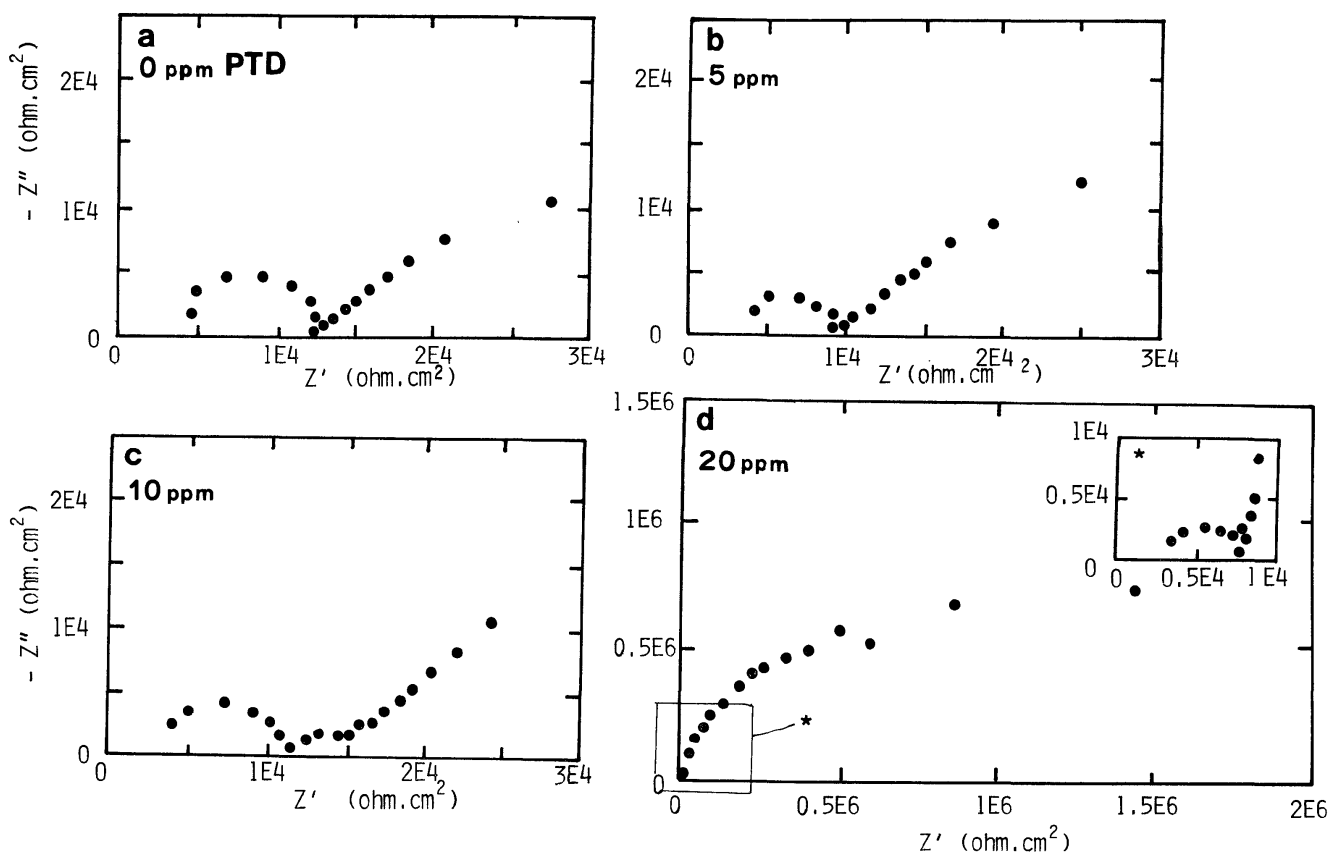

Fig. 6 Nyquist plots for copper electrodes after $24 \mathrm{hr}$ immersion in low conductivity solutions with (a) $0 \mathrm{ppm}$, (b) $5 \mathrm{ppm}$, (c) $10 \mathrm{ppm}$, and (d) $20 \mathrm{ppm}$ PTD.

the middle frequency range, corresponding to the charge transfer process at the CuPTD/ solution interface.

Fig. 6-d shows a much larger semicircle for $20 \mathrm{ppm}$ PTD, and the film resistance $R$, determined from the diameter of the semicircle, increases from $\sim 5 \times 10^{3} \Omega \mathrm{cm}^{2}$ to $1 \times 10^{6} \Omega \mathrm{cm}^{2}$ as PTD concentration increases from $10 \mathrm{ppm}$ to $20 \mathrm{ppm}$. Therefore, the corrosion reaction of copper in the presence of $20 \mathrm{ppm}$ PTD is controlled by the resistance of CuPTD film. It is noted in Fig. 6-d that the high frequency semicircle still remains and its enlarged diagram is exhibited in the inset of Fig. 6-d. The diameter of the high frequency semicircle decreases with increasing PTD concentration because of the increase in solution conductivity caused by PTD. As to the explanation of the high-frequency semicircle and the determination of solution resistance we shall write in a separate paper.

Table 1 shows the relationship between solution conductivity and PTD concentration. Unlike PTD even small amounts of BTA shows marked inhibitive action. Both $|Z|$ and $\theta_{\max }$ increase remarkably from $0.01 \mathrm{ppm}$ to $0.1 \mathrm{ppm}$ BTA. The addition of $0.1 \mathrm{ppm}$ BTA in the solution makes $\theta_{\max }$ close to 40 degrees.

Fig. 7 shows $R$ vs. concentrations of BTA and PTD. It is evident that BTA inhibits cor-
Table 1 Changes in solution conductivity with PTD concentration.

\begin{tabular}{|l|l|l|l|r|r|}
\hline PTD concentration (ppm.) & 0 & 5 & 10 & 20 & 40 \\
\hline conductivity $(\mu \mathrm{mho} / \mathrm{cm})$ & 4 & 5 & 6 & 8 & 12 \\
\hline
\end{tabular}

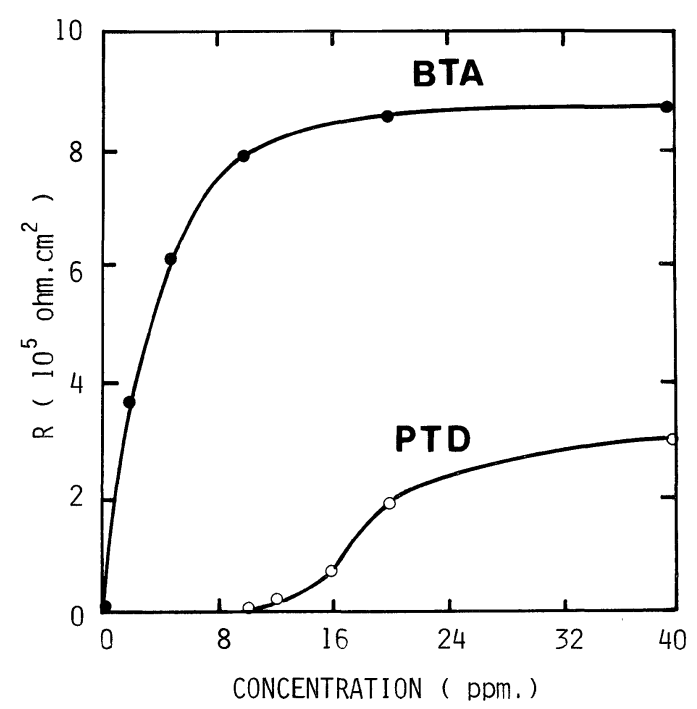

Fig. 7 Influence of BTA and PTD concentration on $R$ after $30 \mathrm{~min}$ immersion at $30^{\circ} \mathrm{C}$.

rosion of copper better than PTD at concentrations up to $40 \mathrm{ppm}$. Experiments with a combination of BTA and PTD at a total concentra- 


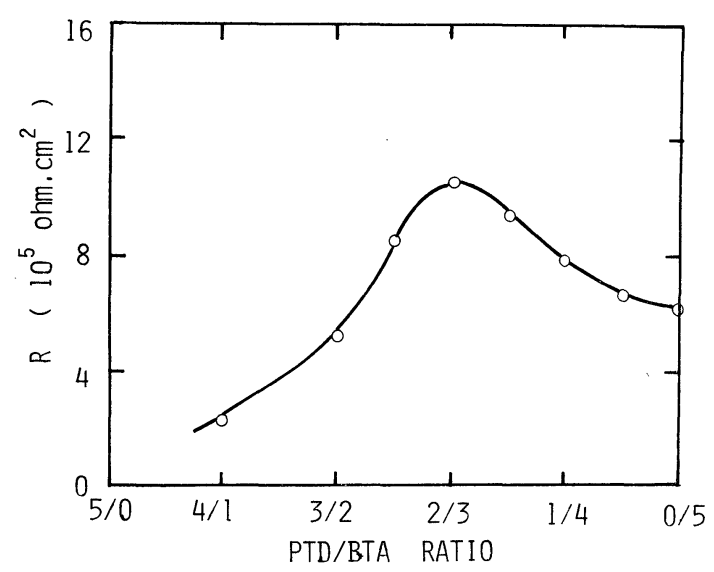

Fig. $8 R$ vs. PTD/BTA ratio for copper electrodes after $30 \mathrm{~min}$ immersion in low conductivity solutions at $30^{\circ} \mathrm{C}$.

tion of $5 \mathrm{ppm}$, which is suitable for practical applications in water cooling generators, were made. The combination of BTA and PTD is more effective than either used alone.

Fig. 8 shows $R$ vs. the PTD to BTA ratio. The maximum value of $R$ is at the 2 ppm PTD to $3 \mathrm{ppm}$ BTA ratio. The value at this ratio is about $10^{6} \Omega \mathrm{cm}^{2}$. The combination of BTA and PTD obviously improves the inhibitive action and shows a synergistic effect. BTA may spread over the surface of copper electrodes and form a protective film consisting of a CuBTA polymeric network ${ }^{6), 9)}$. PTD may then plug defects in the network on $\mathrm{Cu} / \mathrm{Cu}_{2} \mathrm{O}$ by forming CuPTD film.

(Received November 1, 1989)

\section{References}

1) G. Lewis: Corrosion, 34, 424 (1978).

2) F. El-Taib Heakal \& S. Haruyama: Corros. Sci., 20, 887 (1980).

3) F. Mansfeld, M. W. Kendig \& S. Tsai: Corrosion, 38, 570 (1982).

4) F. Mansfeld: ibid., 37, 301 (1981).

5) G. W. Walter: Corros. Sci., 26, 681 (1986).

6) J. B. Cotton \& I. R. Scholes: Brit. Corros. J., 2, 1 (1967).

7) F. Mansfeld \& T. Smith: Corrosion, 29, 105 (1973).

8) K. Mori, Y. Nakamura, M. Okuyama \& M. Miyazaki: Nihon Kagaku Kaishi, No. 6, 786 (1977).

9) T. Notoya: Boshoku Gijutsu (Corrosion Engineering), 27, 661 (1978).

10) Y. Chuga, H. Imokawa, M. Okumura \& M. Miyazaki: Karyoku Gensiryoku Hatsuden, 31, 1063 (1980).

11) T. Notoya: Bosei Kanri (Rust Prevention), 33, 1 (1989).

12) F. Mansfeld, S. Lin, Y. C. Chen \& H. Shin: J. Electrochem. Soc., 135, 906 (1988). 